Cite as: De Brandt J,

Vanfleteren L, Almendros I. Preview of Sleep and Breathing Conference 2019 and report on Early Career Member international collaboration. Breathe 2019; 15: 60-63.

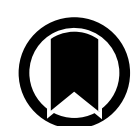

CrossMark

(c)ERS 2019

Early career forum

\title{
Preview of Sleep and Breathing Conference 2019 and report on Early Career Member international collaboration
}

\section{Preview: Sleep and Breathing Conference 2019}

This year the Sleep and Breathing Conference (SBC), organised by the European Respiratory Society (ERS) and the European Sleep Research Society, will take place in Marseille Parc Chanot (Marseille, France) on April 11-13, 2019. The programme of the upcoming 2019 conference includes specialised symposia that cover most sleep disorders: obstructive/central sleep apnoea, narcolepsy, insomnia, circadian disorders and restless legs syndrome, among other related diseases.

This conference will provide the opportunity for Early Career Members to update their knowledge and skills. Most importantly, you can network with pneumologists, basic researchers and other professionals specialising in sleep respiratory medicine and science. The SBC 2019 will cover the main areas detailed in the following sections of this article. The full programme can be found at https://www.sleepandbreathing.org

\section{Diagnostic techniques in adults and children}

There will be a promising session aiming to demonstrate how to perform and interpret sleep studies in both adults and children. The main differences between paediatric and adult polysomnography and polygraphy will be presented.
In addition, the complexities of sleep and respiratory testing will be shown, along with the limitations, advantages and pitfalls.

\section{Mechanisms from clinical and basic science}

Several symposia will present the state of the art in sleep disordered breathing research. For instance, the new insights in the association of obstructive sleep apnoea (OSA) with stroke and dementia, the coexistence of sleep disordered breathing with other respiratory diseases (e.g. chronic obstructive pulmonary disease or hypoventilation syndrome) and the role of hypoxia and the usefulness of oxygen in the pathology of sleep disordered breathing will be addressed in different sessions. In addition, a session will summarise the current findings regarding sex differences in sleep disordered breathing, including pathophysiology, clinical presentation, polysomnography findings and cardiovascular risk, and will discuss sleep disordered breathing in specific situations, such as pregnancy.

\section{Treatment strategies}

The SBC will provide a state-of-the-art overview of current insights into oral appliance therapy for OSA. Also, there will be a session discussing the multiple components that contribute to the clinical and pathophysiological phenotypes of

@ERSpublications

Preview for Early Career Members on the Sleep and Breathing Conference 2019 and report on international collaboration between the European Respiratory Society and the Chinese Thoracic Society http://ow.ly/IUpi30n2DSL 
OSA and presenting new individualised treatment algorithms. The session will also present approaches to difficult clinical situations in specific patient subgroups. In parallel, Meet the expert and Workshop sessions will describe different types of positive pressure airway therapy, to assess the appropriate use of the different therapies, to list different types of positive pressure interfaces and how these may suit different patients, to recognise the concepts of compliance and adherence, and to discuss initiation of continuous positive airway pressure and selection of the appropriate device and interface.

\section{Hot topic debates}

There will also be space for debates on hot topics in sleep medicine. For instance, the current indications for and attitudes towards the management of sleep disordered breathing in a sleep laboratory versus the home will be discussed. Also, a comprehensive overview of the status concerning the application for a driving licence in Europe will be provided, to discuss the data and what is needed for the assessment of sleepiness in drivers with OSA.

\section{International collaboration: Early Career Member representatives visit the Annual Congress of the Chinese Thoracic Society}

One of the main aims of the ERS is international collaboration across European borders. Annually, the Chinese Thoracic Society (CTS) extends invitations to the Early Career Member Committee (ECMC) to attend the Annual Congress of the CTS and to get connected with the CTS Youth Committee. Last August (2018), two Early Career Member representatives (Lowie Vanfleteren from Assembly 1 and Jana De Brandt from Assembly 9; figure 1) were invited, together with President Elect Thierry Troosters, Education Council Chair Daiana Stolz and Executive Director of the ERS Werner Bill, to strengthen and discuss the collaboration between ERS and CTS.

The 2018 Annual Congress of the CTS (August 29 to September 2, 2018) was organised in Suzhou, a city surrounded by beautiful lakes and located about $80 \mathrm{~km}$ from Shanghai. Around 10000 delegates from all over China, and a handful of foreign delegates, attended the congress. At the congress, a special English spoken session was devoted to ERS leadership. ERS President Elect Thierry Troosters presented the European perspective on pulmonary rehabilitation. Education Council Chair Daiana Stolz gave insight into the role of biomarkers in community-acquired pneumonia. Former ERS
President Francesco Blasi was also present and talked about guidelines for bronchiectasis. This special session was well attended and we hope the Chinese delegates were inspired by the ERS leadership (figure 2).

The CTS Youth Committee plays a prominent role within the society as it is responsible for organising the Youth Sessions, presented in English (six sessions, each lasting 2 h, throughout the congress). The Youth Sessions were chaired by CTS Youth Committee members and congress delegates presented their research findings in English. Early Career Member representatives Lowie Vanfleteren and Jana De Brandt were also

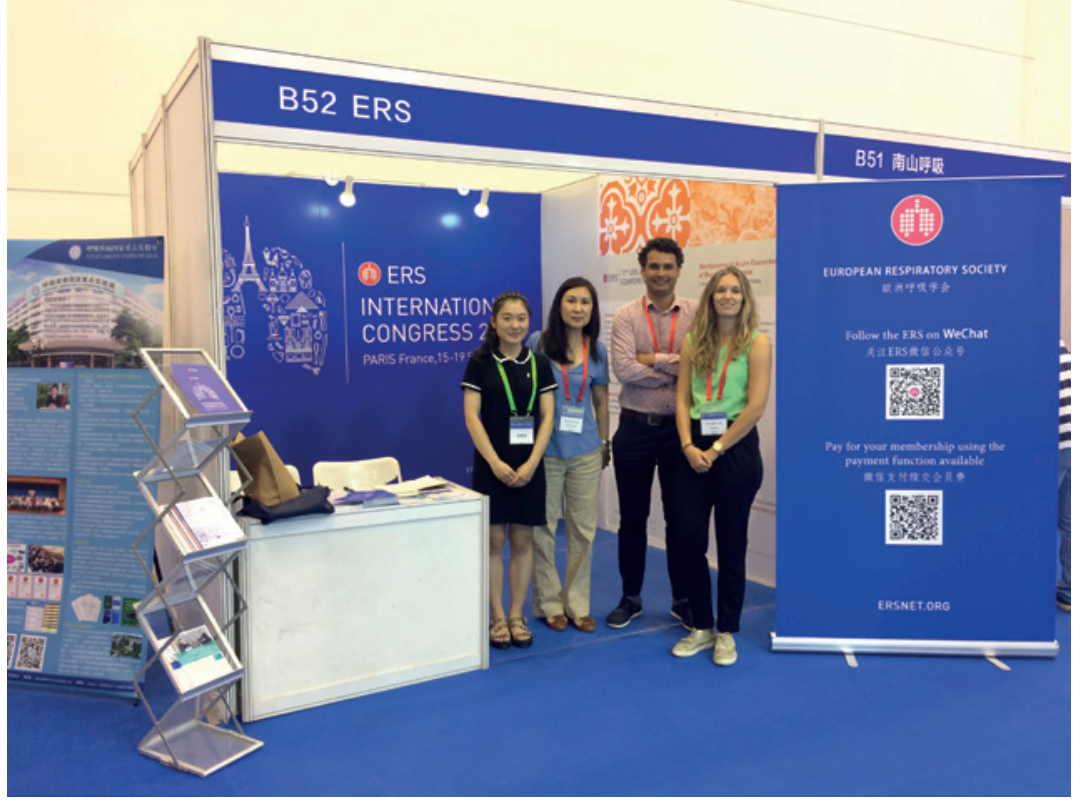

Figure 1 Early Career Member representatives Lowie Vanfleteren (Assembly 1) and Jana De Brandt (Assembly 9) at the ERS booth at the Annual Congress of the CTS.

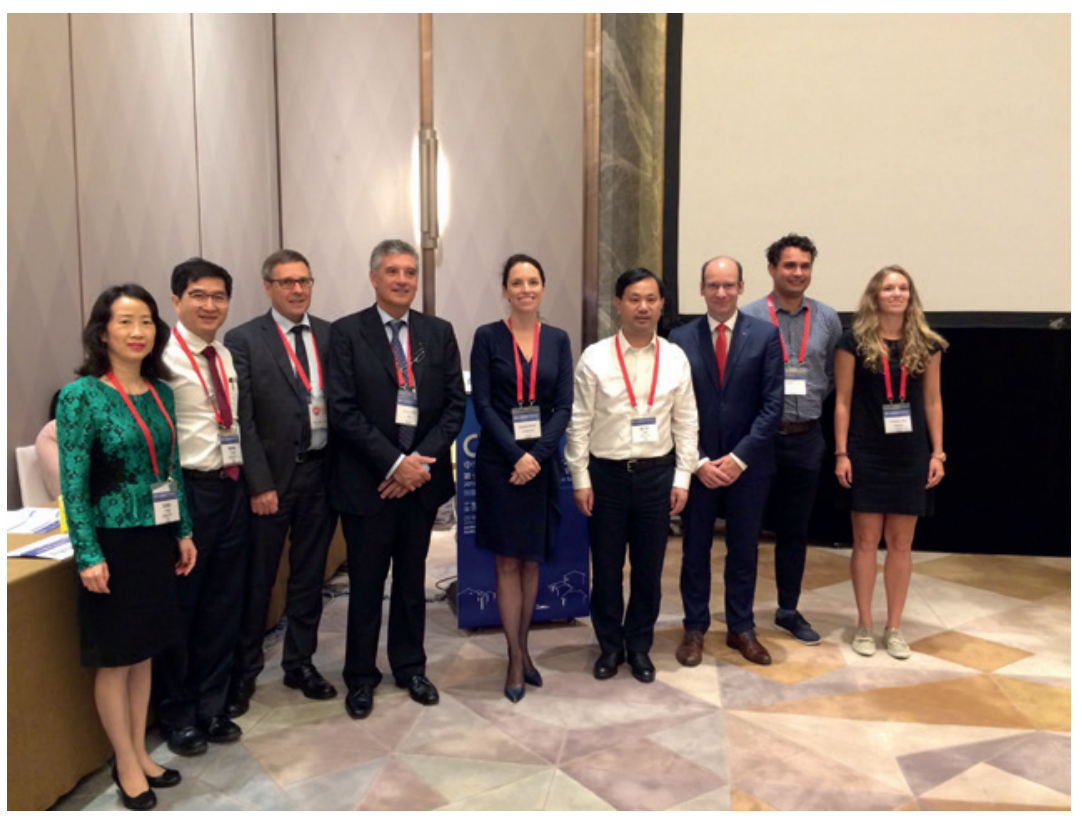

Figure 2 ERS leadership and Early Career Member representatives with the CTS leadership. 


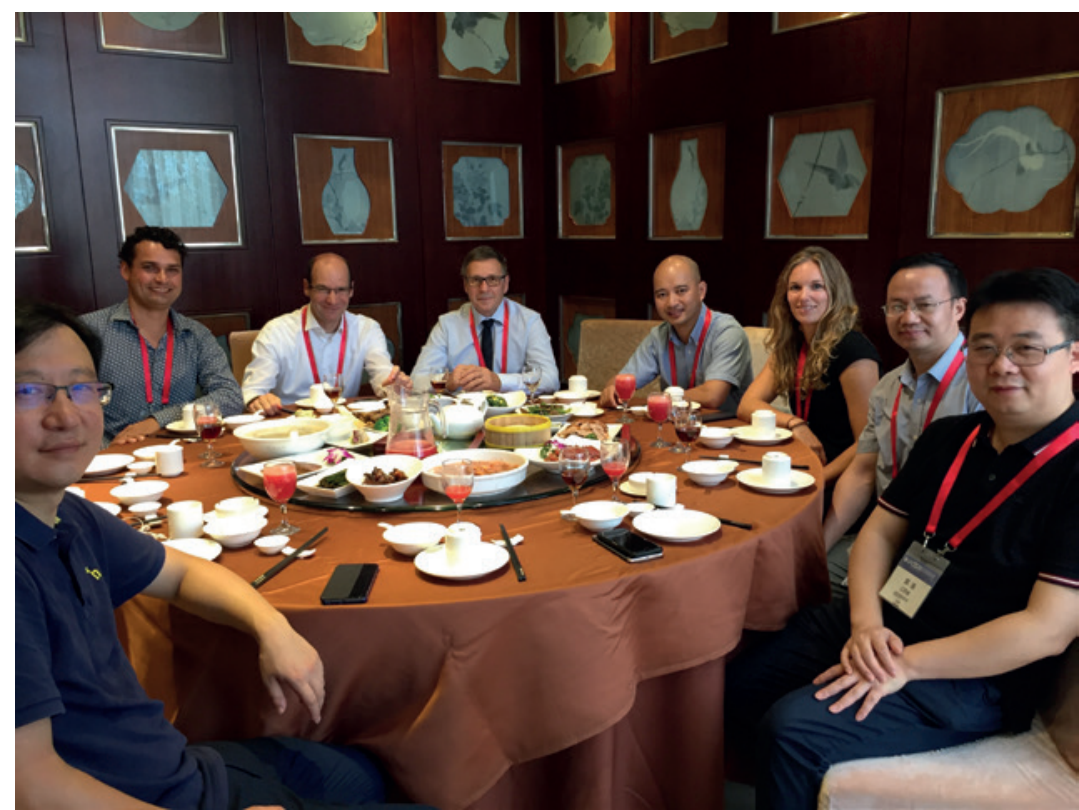

Figure 3 ERS leadership and Early Career Member representatives during a lunch meeting with the CTS Youth Committee.

invited to give a "special report" presentation during these Youth Sessions. Lowie Vanfleteren spoke about the management of comorbidities in patients with chronic obstructive pulmonary disease (COPD) and Jana De Brandt covered how pulmonary rehabilitation can counteract muscle dysfunction in patients with COPD. Both presentations were well attended and inspired discussion. All ERS delegates were impressed by the quality and novelty of the research presented as well as by the English presentation skills of several Chinese delegates. A clear focus within Chinese research lies within the rapidly evolving field of basic science research.

Besides attending the congress, ERS delegates were invited to several dinner meetings to discuss collaboration between the ERS and CTS (figure 3). The head of the CTS Youth Committee, Ying Songming, elaborated on the fact that Chinese clinicians and researchers want to be more involved within the ERS. A fruitful discussion delivered several action points (table 1) that the ERS ECMC and CTS Youth Committee are going to work on in the upcoming years.

In conclusion, we want to thank all the volunteers from the CTS who were readily available to us. We experienced a warm welcome, tasted great Chinese food, and enjoyed the beautiful marriage of Chinese traditional and novel hightech culture. And last but not least, we feel very fortunate that we could experience the Annual Congress of the CTS and we hope that the collaboration between the ERS and CTS will blossom in the future. XièXiè (thank you)!

Table 1 Action points for future collaboration between the CTS Youth Committee and the ERS ECMC

1 Efforts will be made to increase the interaction of Chinese and European early career speakers at each other's congresses

2 The CTS Youth Committee will provide the ERS ECMC with early career Chinese speakers with good English presenting skills and high-quality research output; subsequently, early career Chinese speakers can be more involved within the ERS International Congress programme

3 The CTS Youth Committee will provide topics to be covered in the Youth Sessions (presented in English) at the Annual Congress of the CTS, and the ERS ECMC will suggest ERS early career speakers suitable for the topics

4 A highlights review article summarising award-winning abstracts presented at the Annual Congress of the CTS will be created by the ERS ECMC and the CTS Youth Committee

5 Opportunities for travel grants for CTS early career members to attend the ERS Lung Science Conference and the SBC will be reviewed, as these conferences have a strong basic science research focus

6 A discussion platform will be created between the ERS ECMC and the CTS Youth Committee

\section{Affiliations}

\section{Jana De Brandt ${ }^{1,5}$, Lowie Vanfleteren ${ }^{2,5}$, Isaac Almendros ${ }^{3,4,5}$}

${ }^{1}$ REVAL - Rehabilitation Research Center, BIOMED - Biomedical Research Institute, Faculty of Rehabilitation Sciences, Hasselt University, Diepenbeek, Belgium. ${ }^{2}$ COPD Center, Sahlgrenska University Medical Hospital and Institute of Medicine, Gothenburg University, Gothenburg, Sweden. ${ }^{3}$ Unitat de Biofísica i Bioenginyeria, Facultat de Medicina i Ciències de la Salut, Universitat de Barcelona, Barcelona, Spain. ${ }^{4}$ Centro de Investigación Biomédica en Red de Enfermedades Respiratorias, Madrid, Spain. ${ }^{5}$ All authors contributed equally. 


\section{Conflict of interest}

J. De Brandt has nothing to disclose. L. Vanfleteren reports personal fees from AstraZeneca, Chiesi, Pulmonx, GlaxoSmithKline and Novartis, outside the submitted work. I. Almendros has nothing to disclose.

\section{Support statement}

J. De Brandt is funded by the Flemish government. The research and PhD fellowship of J. De Brandt is sponsored by FWO (Fonds Wetenschappelijk Onderzoek), grant \#11B4718N. 